\begin{tabular}{|l|l|}
\hline Recibido / RecEIVED & 26 de septiembre de 2019 \\
\hline AcEPTAdo / AcEPTED & 13 de marzo de 2020 \\
\hline PÁginas / PAGes & De la 147 a la 150 \\
\hline
\end{tabular}

\title{
Santa desobediencia. Jesuitas entre democracia y dictadura en Chile 1962-1983
}

\author{
Autor / Author \\ SCHNOOR, Antjeje \\ Editorial / Publishing company \\ UNIVERSIDAD ALBERTO HURTADO, Santiago de Chile 2019 \\ DOI: https://doi.org/10.32466/eufv-rel.2020.7.575.147-150
}

\begin{abstract}
A
ntjé Schnoor se aproxima a un periodo concreto de la historia de la Compañía de Jesús en Chile, el comprendido entre 1962 y 1983, a partir de tres consideraciones previas: rechaza como error cualquier análisis que considere a la Iglesia como si se tratase de una institución homogénea en sus estructuras e intereses; considera la estructura internacional tanto de la Iglesia católica como de la Compañía de Jesús y, sobre todo, plantea una hipótesis: para explicar el desarrollo y la actuación de esta última institución es necesario analizarse la forma en la que sus miembros han concebido su ideal de obediencia.

El análisis comienza en torno a los primeros años sesenta, cuando la iglesia chilena rompe con el partido conservador y la revista Mensaje - capital en todo el periodo y en todo el libro- publica su monográfico «Revolución en América» (1962), cuando el padre Aldunate es elegido provincial de Chile (1963), cuando llega al poder Eduardo Frei (1964) y se celebran el Concilio Vaticano II y la Congregación General XXXI de la Compañía de Jesús que elegirá a Pedro Arrupe prepósito general. El estudio concluye veinte años después: Arrupe, enfermo, es incapaz de continuar gobernando la Compañía (1981), monseñor Silva Henríquez deja de ser arzobispo de Santiago (1983) y Fernando Montes provincial jesuita (1984) y, mientras se celebra la Congregación General XXXIII (1983), se inicia una nueva y definitiva fase en la dictadura de Pinochet.

La revista Mensaje es la principal fuente documental del trabajo. No era el órgano oficial de la Compañía, ni recogía todo la diversidad de sus opiniones, como se va viendo a lo largo de la obra, pero sí fue la más influyente y respetada revista eclesial chilena y una de las de mayor difusión en el mundo americano; nació además con un fortísimo apoyo de los superiores y, en otro orden de cosas, fue uno de los pocos órganos escritos opositores al régimen de Pinochet, lo que obliga, como hace la autora, a reflexionar
\end{abstract}


sobre la censura y la autocensura bajo la dictadura y, existiendo ambas, a rastrear la evidente oposición al régimen de este órgano de opinión.

Con mucho acierto, la Iglesia no es analizada como si se tratase de una institución homogénea; sólo puede ser entendida como un actor político complejo. No solo es imposible entender su comportamiento fijando la mirada únicamente en el Vaticano y las estructuras episcopales; es mucho más heterogénea de lo que esto permite suponer: cada congregación tiene sus objetivos, a veces enfrentados en diverso grado a los de otras instituciones eclesiásticas e, incluso, en el seno de una misma institución se manifiestan planteamientos y objetivos contrapuestos. En segundo lugar, Schnoor considera la dimensión multinacional de la Compañía de Jesús. No solo los órganos últimos de gobierno no se encuentran en Chile, los sujetos que trabajan en cada provincia pueden tener orígenes nacionales diversos, pueden haber trabajado en varios países y perciben como propios o, al menos, próximos los problemas y los desafíos de sus hermanos en el mundo. Nulo sería cualquier análisis que no tuviera en cuenta los procesos desarrollados y las decisiones tomadas fuera de la república.

Con todo, el elemento fundamental del que parte Schnoor es la transformación del ideal de obediencia jesuítica, desarrollado en el seno de un amplio proceso. Schnoor no entiende la obediencia como una actitud ahistórica e inmutable que perteneciera a una eventual identidad jesuita, sino, al contrario, como una construcción vinculada al tiempo. En su análisis parte de que, teológicamente, solo la libertad hace al hombre capaz de obedecer, y de una distinción entre una obediencia de orden o institucional, es decir, la subordinación a la autoridad; una obediencia religiosa, que se relaciona con la fe y es obediencia a la voluntad de Dios; una obediencia como virtud, relacionada con la autoridad de la razón y en el seno de la tradición jesuita, la distinción entre una obediencia ascética, que tendría valor en sí misma, y una obediencia apostólica, como medio para un apostolado más efectivo.

Desde este planteamiento, la reinterpretación de la obediencia tiene que ver con el rechazo a una obediencia ciega que implica la renuncia a la propia responsabilidad (capital tras las reflexiones nacidas como respuesta a los regímenes totalitarios que se desarrollaron en Europa en el segundo cuarto del siglo xx), las implicaciones eclesiológicas y políticas del Concilio Vaticano II, tanto en lo que tiene que ver con su análisis de la democracia política como en su esfuerzo por reconciliarse con la modernidad. El esfuerzo por reinterpretar la obediencia se relaciona, por un lado, con una relectura de la tradición ignaciana que - más allá de los objetivos de Schnoor - se vincularía con el papel jugado, a lo largo de los siglos, por el esfuerzo historiográfico en la configuración de la identidad jesuita, y, por otro, con un nuevo ideal que llama al diálogo del superior con sus súbditos, a la argumentación de las órdenes y al valor de la conciencia; sin pretender, como señala la Congregación General XXXI, reducir la obediencia a un mero acto racional.

Este proceso se vincula profundamente a toda la acción pastoral estructurada sobre la opción preferencial de promoción de la justicia que se hizo nuclear en la Congregación General XXXII, no ya como responsabilidad o tarea individual de algunos jesuitas, sino como compromiso de toda la orden. Esta transformación se desarrolló en medio de múltiples conflic- 
tos, en el seno de la Compañía y entre esta y la autoridad romana; para el caso español acaba de aparecer un análisis, franco e interesante, Pablo VI y los jesuitas, obra de Urbano Varelo Agúndez, que fue provincial en España.

Si estas son las consideraciones teóricas, el desarrollo del análisis de Schnoor multiplica el interés de su obra.

Tras la ruptura con el partido conservador, el núcleo mayoritario de la iglesia chilena y, en su seno, la mayoría de los jesuitas se vincularon estrechamente al proyecto demócrata cristiano y, por lo menos hasta su victoria electoral, a los objetivos de Eduardo Frei, legitimándolos incluso a través del ideal de una revolución en libertad que implicaba, entre otras grandes reformas sociales, la agraria y la nacionalización del cobre. Es más, según la autora, los jesuitas serían los principales impulsores de apoyo episcopal a Frei, en una época de fuerte anticomunismo y de temor ante la alianza izquierdista de la FRAP. Se había producido una radical mutación frente a los tiempos en los que jesuitas como Fernando Vives, José Fernando Pradel o Alberto Hurtado eran marginales, problemáticos e, incluso, mal vistos por buena parte del catolicismo chileno. Se trataba ahora de una revolución desde arriba, cristianizada y abiertamente diferenciada del sueño cubano.

A lo largo de la obra se apuntan algunos efectos, de división y desprestigio, asociados a esta colaboración; lo que no se observan son los motivos de la posterior ruptura, más allá de la frustración experimentada ante las excesivas expectativas que en Frei habían depositado grupos eclesiales, sectores sociales e, incluso, corrientes internas de la misma democracia cristiana.

Derrotada electoralmente la democracia cristiana, el triunfo de Allende no fue recibido con neutralidad por el episcopado. Si la jerarquía episcopal había reconocido, casi de forma inmediata, como presidente a todos los que con anterioridad habían ganado las elecciones, con independencia de que gozaran, en principio, de una mayoría parlamentaria, Raúl Silva Henríquez no quiso actuar así y espero a su proclamación formal. Mensaje, por el contrario, si le reconoció de forma inmediata. Estas diferencias de criterio no impiden que, básicamente, Mensaje, durante la presidencia de Allende y la dictadura, contribuyese a reforzar la posición del arzobispo frente a las divisiones eclesiales, tradicionalistas y revolucionaria. No cabe ignorar que la llegada de Allende al poder fue paralela a la ruptura, en el seno de la Compañía, entre Arroyo, líder de Cristianos por el Socialismo, y Vekemans, pronto exiliado a Colombia y uno de los principales responsables de la reacción eclesial contra la Teología de la Liberación.

Pese a las distancias, bajo la dictadura de Pinochet se reconstruyen las relaciones entre la Compañía y el episcopado. Mensaje, como Silva Enríquez, aceptó la legitimidad del golpe, pero pidió, desde el principio la rápida vuelta a la democracia. Lentamente, y con todas las limitaciones lógicas, fue manifestándose muy crítica ante la violación de los derechos humanos por parte del poder militar. Pero el proceso no caracterizó al conjunto de la iglesia chilena, ni tan siquiera a la totalidad de la Compañía. Se puso de manifiesto la heterogeneidad de posturas, existiendo tanto enemigos como partidarios de Pinochet.

Son muchas más las cuestiones que este libro contribuye a esclarecer. Entre ellas destaca la reacción eclesial ante la publicación de la Humanae vitae; el papel, en gran medida nove- 
doso, que los teólogos estaban jugando en el interior de la Iglesia; la tensión y la colaboración de la Compañía, como institución y considerando a varios de sus miembros, con el episcopado que, por su parte, ha cobrado una dimensión nueva desde la implantación de las conferencias episcopales; la posición ventajosa en la que actúa el clero nacional jesuita, unido por vínculos familiares a sectores sociales poderosos, frente al extranjero, mucho más indefenso ante la violenta arbitrariedad de la dictadura; la evidente distancia que la Compañía y la revista Mensaje, en la línea de hombres como Ignacio Ellacuría, marcan con respecto a Cristianos por el Socialismo, estando las primeras mucho más próximas a la reflexión tradicional católica en torno al recurso político a la violencia, mientras $C p S$ estaba influido por corrientes abiertamente revolucionarias. Si bien es cierto, que Schnoor no analiza con claridad las diferencias entre las múltiples corrientes de la Teología de la Liberación y las posiciones políticas de CpS.

No menos interesantes son las reflexiones en torno a la llamativa personalidad de Arrupe. No cabe ignorar, como señala la autora, que, siendo acusado por muchos, en el Vaticano y en el interior de la Compañía, de ejercer un liderazgo débil, fue elegido - cinco veces consecutivas - presidente de la Unión de Superiores Generales; su forma de liderazgo no debió parecer débil ni estéril entre la gran mayoría de las órdenes religiosas.

Una y otra vez, la lectura de esta obra, sin duda alguna de gran interés, apunta la necesidad de establecer comparaciones con los procesos desarrollados en otros países: cabe preguntarse por la diversidad de soluciones que la Compañía dio al problema de sus colegios, observando, por ejemplo, la situación del colegio Patria, en México, y El Bosque, en Chile; cabe establecer claros paralelismos entre la evolución de Mensaje y la de otros órganos jesuitas semejantes, como la centroamericana ECA; etc. Con mucho más dramatismo hay que analizar el comportamiento del clero castrense, en Argentina y Chile, dispuesto siempre a ignorar y legitimar la violencia dictatorial.

Las grandes cuestiones que este libro considera y, lógicamente, no cierra son, por un lado, la actuación de la iglesia en las dictaduras y, por otro, la dificultad para establecer barreras entre la legítima actuación política del clero y la Iglesia y el clero y una discutible acción partidista, llena de inevitables implicaciones. Muy poco resuelve la respuesta teórica que algunos han dado: afirmar que la acción política del sacerdote sería lícita, siempre que no pretenda ejecutarla ni legitimarla recurriendo a su condición o autoridad sacerdotal.

\section{GÓMEZ DÍEZ, Francisco Javier}

